\title{
Reduction in Occupational and Patient Radiation Exposure from Myocardial Perfusion Imaging: Impact of Stress-Only Imaging and High-Efficiency SPECT Camera Technology
}

\author{
W. Lane Duvall ${ }^{1}$, Krista A. Guma ${ }^{1}$, Jacob Kamen ${ }^{2}$, Lori B. Croft ${ }^{1}$, Michael Parides ${ }^{3}$, Titus George ${ }^{1}$, and Milena J. Henzlova ${ }^{1}$ \\ ${ }^{I}$ Mount Sinai Division of Cardiology (Mount Sinai Heart), Mount Sinai Medical Center, New York, New York; ${ }^{2}$ Mount Sinai \\ Department of Radiology, Mount Sinai Medical Center, New York, New York; and ${ }^{3}$ Mount Sinai Department of Health Evidence \\ and Policy, Mount Sinai Medical Center, New York, New York
}

Recently introduced high-efficiency SPECT cameras have demonstrated the ability to reduce radiation exposure to patients undergoing myocardial perfusion imaging studies, especially when combined with stress-only imaging protocols. To date there have been no relevant studies examining the reduced occupational radiation exposure to medical staff. We sought to determine whether changes in stress myocardial perfusion imaging protocols and camera technology can reduce the occupational radiation exposure to the staff of a nuclear cardiology laboratory. Methods: Monthly radiation dosimeter readings from 4 nuclear technologists, 4 nurses, and 2 administrative employees were analyzed from two 12-mo periods: October 2007-September 2008 (period 1), before the use of high-efficiency SPECT, and October 2010-September 2011 (period 2), after high-efficiency SPECT was introduced. The average monthly dose equivalent in millirems $(1 \mathrm{mrem}=0.01 \mathrm{mSv})$ was recorded from personal dosimeters worn on laboratory coats. The total activity of ${ }^{99 \mathrm{~m} T c}$ used per month, mean ${ }^{99 \mathrm{~m} T c}$ administered activity per patient, average number of patients per month, patient time spent in the laboratory, and proportion of stress-only studies were determined. Results: There were 3,539 patients in period 1 and 3,898 in period 2 . An approximately $40 \%$ reduction in the dose equivalent across all staff members occurred during this time $(-16.9$ and -16.2 mrem for nuclear technologists and nurses, respectively; $P<0.0001$ ). During period 2 , the total activity of ${ }^{99 \mathrm{mTC}}$ used per month decreased (10,746 vs. $7,174 \mathrm{mCi}[1 \mathrm{mCi}=37 \mathrm{MBq}]$, $P<0.0001$ ), as did the mean ${ }^{99 m T c}$ administered activity per patient (36.5 vs. $23.8 \mathrm{mCi}, P<0.0001)$. The percentage of patients having stress-only imaging increased $(35 \%$ vs. $56 \%, P$ $<0.0001$ ), and the total patient time spent in the laboratory decreased. Radiation dose equivalent levels were reduced in period 2 to $1 \%-7 \%$ of the allowed annual occupational dose equivalent. The combination of the use of high-efficiency SPECT technology and stress-only protocols resulted in a $34.7 \%$ reduction in mean total ${ }^{99 m} \mathrm{Tc}$ administered activity between time periods, with camera technology being responsible for $39.2 \%$ of the reduction and stress-only protocols for $60.8 \%$. Conclusion: $A$ combination of high-efficiency SPECT technology and selective use of stress-only protocols significantly reduces the occupational radiation dose equivalent to the staff of a nuclear cardiology laboratory.

Received Aug. 17, 2012; revision accepted Feb. 11, 2013.

For correspondence or reprints contact: Milena J. Henzlova, Mount Sinai Medical Center, Box 1030, One Gustave L. Levy Place, New York, NY 10029. E-mail: milena.henzlova@mountsinai.org

Published online May 30, 2013.

COPYRIGHT (C) 2013 by the Society of Nuclear Medicine and Molecular Imaging, Inc.
Key Words: radiation exposure; myocardial perfusion imaging; high-efficiency SPECT; stress-only imaging

J Nucl Med 2013; 54:1251-1257

DOI: 10.2967/jnumed.112.112680

$\mathbf{R}$ adiation exposure to patients from diagnostic imaging has recently been a prominent topic in the cardiac imaging literature (1), and myocardial perfusion imaging (MPI) has been suggested as one of the larger contributors to a patient's cumulative radiation exposure (2). Much recent effort has been directed toward reducing exposure to the patient (3); however, little attention has been paid to exposure of the medical staff to radiation. There is scant literature on medical staff exposure and even less on methods to reduce this exposure. Sound practice and regulatory agencies require keeping the radiation exposure to workers as low as reasonably achievable.

Recently introduced high-efficiency cadmium zinc telluride (CZT) SPECT camera systems, and iterative reconstruction with depth-dependent resolution recovery (so-called half-time imaging) used with conventional SPECT cameras, have been shown to reduce administered patient isotope activity during MPI (4-8). The Discovery NM 530c (GE Healthcare) high-efficiency cardiac camera, which is based on multipinhole design and an array of CZT pixilated detectors with optimized acquisition geometry and reconstruction software (9), shows great promise at reducing radiation exposure to medical staff during MPI studies.

A stress-only imaging protocol can decrease the length of the test, both for the patients and for the laboratory, and results in a lower radiation dose to the patient and the medical staff. A stress-only study can be completed, processed, and read in less than $90 \mathrm{~min}$ as opposed to the traditional 3-5 h. The radiation dose can be decreased by $30 \%-60 \%$ depending on the dose used for stress imaging $(10,11)$. A normal SPECT MPI study is defined as a negative electrocardiographic response with adequate exercise or vasodilator stress, the absence of stress perfusion defects, and normal left ventricular function. With normal stress images, rest images provide no additional prognostic or diagnostic value and eliminating the rest images becomes possible. The benign prognosis of normal results from a stress-only study has now been confirmed in more than 10,000 patients and appears to be no different from that of normal results from a rest-stress study (10-12). 
We sought to determine how these 2 methods of reducing radiation exposure to patients would affect radiation exposure to the medical staff in a nuclear cardiology laboratory. To our knowledge, no studies have examined the effect of new SPECT camera technology and new stress protocols on occupational radiation exposure to medical staff. We chose to examine the radiation exposure to nurses, nuclear technologists, and administrative staff from 2 periods, before and after the implementation of these changes.

\section{MATERIALS AND METHODS}

\section{Study Design}

In a study protocol approved by the Mount Sinai Institutional Review Board, monthly radiation dosimeter readings from full-time employees (4 nuclear technologists, 4 nurses, and 2 administrative employees) were analyzed from two 12-mo periods. Signed informed consent was obtained from all employees who participated in this study. The same employees worked during both periods, performing identical jobs and serving as their own comparators. The first period was from October 2007 through September 2008, which was before the use of the new high-efficiency SPECT cameras and before more frequent use of stress-only protocols. During this period, 3 conventional SPECT cameras were in use. The second period was from October 2010 through September 2011, when high-efficiency SPECT cameras were used and stress-only imaging protocols were more frequent. During this period, 2 high-efficiency SPECT cameras were preferentially used for patients, with a single conventional SPECT camera reserved for patients who could not be positioned in the smaller high-efficiency camera. Monthly measures of radiation dose equivalent to the medical staff were collected from personal dosimeters (badges) worn on laboratory coats.

In our noninvasive cardiology laboratory, registered nurses are responsible for taking the patient's history, performing the physical examination, and obtaining informed consent before beginning the study. Nurses also place intravenous catheters and supervise the stress and recovery portions of the test. Nuclear technologists are responsible for preparing and administering both rest and stress isotope doses as well as performing and processing rest and stress imaging studies. Technologists are present in the stress room during the essential part of the stress test and for the initial part of the recovery period to ensure patient stability after isotope injection. These technologists worked only in the noninvasive cardiology laboratory and spent no time in general nuclear medicine. The administrative employees function as receptionists and schedulers at the front desk, which is part of the waiting area, and have no direct patient care responsibilities.

For all patients, demographic and stress test variables were prospectively collected in the nuclear cardiology database at the time of stress testing. The total activity of ${ }^{99 \mathrm{~m}} \mathrm{Tc}$ and ${ }^{201} \mathrm{Tl}$ used per month, mean dose per patient, average number of patients per month, patient time spent in the laboratory, and proportion of stress-only studies were determined. Total patient time in the laboratory was calculated by allotting $60 \mathrm{~min}$ for a rest-only study, $90 \mathrm{~min}$ for a stress-only study, $3.5 \mathrm{~h}$ for a rest-stress study, and $4 \mathrm{~h}$ for a stress-rest study.

\section{Personal Dosimeters}

Radiation badges (Luxel+; Landauer) were worn by all laboratory personnel on laboratory coats and were positioned on the front of the trunk, between the neck and the waist. Adherence to noninvasive laboratory policy regarding mandatory use of personal dosimeters is enforced by the laboratory supervisor. These radiation badges have the sensitivity to measure as low as $1 \mathrm{mrem}(1 \mathrm{mrem}=0.01 \mathrm{mSv})$. The deep-dose equivalent is generally considered a measure of the mean whole-body dose equivalent from an external source of ionizing radiation. This value is the dose equivalent at a tissue depth of $1 \mathrm{~cm}$. On the basis of the manufacturer's specifications, this value is equal to the total effective dose equivalent because it is a measure of the whole-body exposure. The shallow-dose equivalent is the external dose to the skin of the whole body or extremities from an external source of ionizing radiation. This value is the dose equivalent at a tissue depth of $0.007 \mathrm{~cm}$ averaged over an area of $1 \mathrm{~cm}^{2}$. The lens-dose equivalent is the dose equivalent to the lens of the eye from an external source of ionizing radiation. This value is the dose equivalent at a tissue depth of $0.3 \mathrm{~cm}$.

\section{Imaging and Stress Protocols}

A standard imaging protocol as endorsed by the American Society of Nuclear Cardiology was used for all patients (13). A rest-stress or stress-first imaging sequence was applied using ${ }^{99 \mathrm{~m}} \mathrm{Tc}$-sestamibi. If stress-first images demonstrated normal perfusion and normal left ventricular function, rest imaging was not performed. A stressredistribution imaging sequence was applied using ${ }^{201} \mathrm{Tl}$. Redistribution images were not obtained if stress perfusion and left ventricular function were normal. If stress imaging showed abnormal results, then a clinical decision was made to manage the patient medically, perform subsequent rest or redistribution imaging, or refer the patient for cardiac catheterization. ${ }^{201} \mathrm{Tl}$ use in period 2 was based mostly on ${ }^{99 \mathrm{~m}} \mathrm{Tc}$ shortages but was chosen specifically in selected patients for myocardial viability detection.

Gated SPECT imaging was performed using 1 of 2 SPECT cameras. The first was a high-efficiency camera (Discovery NM 530c; GE Healthcare) with a multiple-pinhole collimator that had 19 stationary CZT detectors simultaneously imaging 19 cardiac views without detector or collimator motion. Images were reconstructed using a penalized maximum-likelihood iterative method. The second was a conventional dual-head camera (Vertex Plus; Philips/ADAC Laboratories) with a Vertex general-purpose collimator. Images were obtained using stop-and-shoot acquisition with 64 stops, a $180^{\circ}$ arc from right anterior oblique to left anterior oblique, a $64 \times 64 \times 16$ matrix, and iterative reconstruction. Image acquisition began 30 $60 \mathrm{~min}$ after tracer injection for ${ }^{99 \mathrm{~m}} \mathrm{Tc}$ and $10 \mathrm{~min}$ after injection for ${ }^{201} \mathrm{Tl}$. Post-stress images were gated at rest. Left ventricular ejection fraction was determined using commercial software (QGS; Cedars-Sinai).

${ }^{99 \mathrm{~m}} \mathrm{Tc}$ was obtained from a technetium generator $\left({ }^{99} \mathrm{Mo}\right)$, and ${ }^{201} \mathrm{Tl}$ doses were obtained as unit doses from a local radiopharmacy. The administered radionuclide activity was weight-adjusted and was dependant on the protocol performed. For the conventional SPECT camera in period 1, the standard 1-d rest-stress ${ }^{99 \mathrm{~m}} \mathrm{Tc}$ protocol used a rest dose of $8-13 \mathrm{mCi}(1 \mathrm{mCi}=37 \mathrm{MBq})$ based on 4 weight groups ( $\leq 56.0 \mathrm{~kg}, 56.4-74.6 \mathrm{~kg}, 75.0-93.3 \mathrm{~kg}$, and $>93.3 \mathrm{~kg}$ ) and a stress dose of 25-38 mCi based on the same weight groups. The stress-only ${ }^{99 \mathrm{~m}} \mathrm{Tc}$ protocol used a low dose of $12.5-15 \mathrm{mCi}$ if the weight was 56.0 $\mathrm{kg}$ or less and a high dose of $25-38 \mathrm{mCi}$ based on 3 weight groups ( $\leq 74.6 \mathrm{~kg}, 75.0-93.3 \mathrm{~kg}$, and $>93.3 \mathrm{~kg}$ ). The standard 1-d stressredistribution ${ }^{201} \mathrm{Tl}$ protocol used $3.5-4.5 \mathrm{mCi}$ based on 4 weight groups ( $\leq 56.0 \mathrm{~kg}, 56.4-74.6 \mathrm{~kg}, 75.0-93.3 \mathrm{~kg}$, and $>93.3 \mathrm{~kg}$ ). For the CZT SPECT camera in period 2, the standard 1-d rest-stress ${ }^{99 \mathrm{~m}} \mathrm{Tc}$ protocol used a rest dose of $5-10 \mathrm{mCi}$ based on 3 weight groups $(<74.6 \mathrm{~kg}, 74.6-93.3 \mathrm{~kg}$, and $>93.3 \mathrm{~kg})$ and a stress dose of $15-30$ $\mathrm{mCi}$ based on the same weight groups. If needed, the rest dose for a 1-d stress-rest ${ }^{99 \mathrm{~m}} \mathrm{Tc}$ protocol was $15-30 \mathrm{mCi}$ based on 3 weight groups $(<74.6 \mathrm{~kg}, 74.6-93.3 \mathrm{~kg}$, and $>93.3 \mathrm{~kg})$ whereas the rest dose for a 2-d stress-rest ${ }^{99} \mathrm{~m}$ Tc protocol was $10-25 \mathrm{mCi}$ based on the same weight groups. For the standard 1-d stress-redistribution ${ }^{201} \mathrm{Tl}$ protocol, the dose was $2.5-3.5 \mathrm{mCi}$ based on 3 weight groups $(<56.0 \mathrm{~kg}$, $56.0-74.6 \mathrm{~kg}$, and $>74.6 \mathrm{~kg}$ ). 
Attenuation reduction using prone in addition to supine stress imaging was applied for the high-efficiency SPECT camera, and attenuation correction with a ${ }^{153} \mathrm{Gd}$ line source (Vantage Pro; Philips/ ADAC) was applied for the conventional SPECT camera. These techniques were applied routinely for all studies performed with the respective camera systems.

Standard exercise and pharmacologic protocols as endorsed by the American Society of Nuclear Cardiology were used (14). Exercise testing was performed according to the Bruce or modified Bruce protocol, with heart rate, blood pressure, and 12-lead electrocardiogram recorded before, during, and after exercise. Exercise was terminated when limiting cardiac symptoms occurred or when there was a greater than 2-mm horizontal or downsloping ST segment depression $80 \mathrm{~ms}$ after the J-point over at least 3 consecutive beats.

All pharmacologic stressors except regadenoson were given using weight-based protocols with an upper dose limit of $136 \mathrm{~kg}$; patients exceeding the upper limit received a dose based on a weight of $136 \mathrm{~kg}$. Adenosine was administered as a 6-min infusion at $140 \mu \mathrm{g} /$ $\mathrm{kg} / \mathrm{min}$, which could be reduced to $110 \mu \mathrm{g} / \mathrm{kg} / \mathrm{min}$ if severe symptoms or hemodynamic effects were encountered. Dipyridamole was infused over $4 \mathrm{~min}$ at a dose of $0.56 \mathrm{mg} / \mathrm{kg}$. Regadenoson was administered as a $0.4 \mathrm{mg} / 5 \mathrm{~mL}$ bolus followed by a $5-\mathrm{mL}$ saline flush. The dobutamine protocol consisted of an initial infusion of $5 \mu \mathrm{g} / \mathrm{kg} / \mathrm{min}$, increasing incrementally every $3 \mathrm{~min}$ to $40 \mu \mathrm{g} / \mathrm{kg} / \mathrm{min}$ to achieve a target heart rate of more than $85 \%$ of predicted maximal.

\section{Statistics}

Continuous variables are presented as mean $\pm \mathrm{SD}$. Comparisons among continuous variables were done using 2-tailed $t$ tests (paired and unpaired), and $\chi^{2}$ tests were used to compare categoric variables. A $P$ value of less than 0.05 was considered significant.

Average monthly deep-, shallow-, and lens-dose equivalents were calculated for each of the groups-nurses, nuclear technologists, and administrative staff-and a 2-tailed paired $t$ test was used to compare means. Statistical analysis was performed using Instat 3.1 (GraphPad).

\section{RESULTS}

\section{Demographics}

The characteristics of the patients undergoing SPECT MPI during the 2 periods are presented in Table 1 . There were a total of 3,539 patients in period 1 and 3,898 in period 2 who underwent stress MPI in the noninvasive cardiology laboratory. The average age was $64 \mathrm{y}$, and men represented a slight majority. Although weight and body mass index did not change significantly between periods, more ${ }^{201} \mathrm{Tl}$ was used in period 2 and the proportion of pharmacologic stress procedures increased. Most notably, the average total ${ }^{99 \mathrm{~m}} \mathrm{Tc}$ administered activity decreased (change of 12.7 $\mathrm{mCi}$, or $34.8 \% ; P<0.0001$ ), and the proportion of patients undergoing a stress-only protocol increased $(34.5 \%$ vs $55.5 \%, P<$ $0.0001)$.

\section{Personal Dosimeter Data}

There was an approximately $40 \%$ reduction in monthly recorded radiation dose equivalent across all staff members between period 1 and period 2 (Table 2). The average monthly deep-dose equivalent in the nurse group and nuclear technologist group decreased by just under $40 \%$, whereas the lens-dose and shallow-dose equivalents decreased by just over $40 \%$. The radiation dose equivalent of the administrative staff, although low to begin with, also showed a decrease of $20 \%-40 \%$.

The annual dose equivalents were calculated and are presented in Table 3. The occupational limit for deep-dose equivalent is 5 rems $(5,000 \mathrm{mrem})$, and the nurses and technologists averaged between 490 and 530 mrem annually in period 1 and between 290 and 330 mrem in period 2. The period 2 values represent $6 \%$ of the acceptable annual total. The annual limit for lens-dose equivalent is 15 rems $(15,000 \mathrm{mrem})$, and the nurses and technologists averaged between 500 and 550 mrem annually in period 1 and between 290 and 330 mrem in period 2. The period 2 values

TABLE 1

Demographics, Administered Activity, and MPI Characteristics During the 2 Periods

\begin{tabular}{|c|c|c|c|}
\hline Characteristic & Period 1 (before) $(n=3,539)$ & Period 2 (after) ( $n=3,898$ ) & $P$ \\
\hline Age $(y)$ & $63.4 \pm 13.5$ & $63.6 \pm 12.7$ & 0.51 \\
\hline $\operatorname{Sex}(n)$ & & & $<0.0001$ \\
\hline Male & 1,777 (50.2\%) & $2,164(55.5 \%)$ & \\
\hline Female & $1,762(49.8 \%)$ & $1,734(44.5 \%)$ & \\
\hline Weight (kg) & $81.1 \pm 21.5$ & $81.3 \pm 20.7$ & 0.71 \\
\hline Body mass index $\left(\mathrm{kg} / \mathrm{m}^{2}\right)$ & $28.5 \pm 7.2$ & $28.5 \pm 7.4$ & $>0.99$ \\
\hline Isotope $(n)$ & & & $<0.0001$ \\
\hline $99 \mathrm{mTc}$ & $3,530(99.7 \%)$ & $3,615(92.7 \%)$ & \\
\hline 201TI & $9(0.3 \%)$ & $283(7.3 \%)$ & \\
\hline \multicolumn{4}{|l|}{ 99mTc activity (mCi) } \\
\hline Stress dose & $29.3 \pm 5.9$ & $19.6 \pm 7.0$ & $<0.0001$ \\
\hline Rest dose & $11.3 \pm 4.1$ & $9.5 \pm 6.9$ & $<0.0001$ \\
\hline Total dose & $36.5 \pm 10.0$ & $23.8 \pm 10.6$ & $<0.0001$ \\
\hline${ }^{201} \mathrm{Tl}$ activity (mCi), total dose & $3.8 \pm 0.34$ & $2.7 \pm 0.34$ & $<0.0001$ \\
\hline \multicolumn{4}{|l|}{ Protocol $(n)$} \\
\hline Full study & $2,301(65.0 \%)$ & $1,724(44.2 \%)$ & $<0.0001$ \\
\hline Stress only & 1,222 (34.5\%) & $2,163(55.5 \%)$ & $<0.0001$ \\
\hline Rest only & $16(0.5 \%)$ & $11(0.3 \%)$ & 0.31 \\
\hline Stressor $(n)$ & & & $<0.0001$ \\
\hline Exercise & $1,706(48.2 \%)$ & $1,618(41.5 \%)$ & \\
\hline Pharmacologic & $1,833(51.8 \%)$ & $2,280(58.5 \%)$ & \\
\hline
\end{tabular}

Full study includes both rest-stress and stress-rest protocols of 1- or 2-d duration. 
TABLE 2

Average Radiation Exposure by Staff Position in Millirems Based on 12 Months of Monthly Readings

\begin{tabular}{|c|c|c|c|c|}
\hline Parameter & Period 1 (before) & Period 2 (after) & Change & $P$ \\
\hline \multicolumn{5}{|c|}{ Average monthly deep-dose equivalent } \\
\hline Nurse & $40.6 \pm 11.1$ & $24.5 \pm 7.1$ & $-16.2(-39.8 \%)$ & $<0.0001$ \\
\hline Technologist & $44.0 \pm 11.4$ & $27.1 \pm 7.7$ & $-16.9(-38.4 \%)$ & $<0.0001$ \\
\hline Administrative & $3.6 \pm 2.0$ & $2.3 \pm 1.5$ & $-1.4(-37.7 \%)$ & 0.002 \\
\hline \multicolumn{5}{|c|}{ Deep-dose equivalent per 1,000 patients } \\
\hline Nurse & $139.1 \pm 18.0$ & $75.1 \pm 8.1$ & $-64.1(-46.1 \%)$ & $<0.0001$ \\
\hline Technologist & $149.6 \pm 19.7$ & $87.0 \pm 14.7$ & $-62.5(-41.8 \%)$ & $<0.0001$ \\
\hline Administrative & $12.4 \pm 5.8$ & $7.0 \pm 2.2$ & $-5.4(-43.5 \%)$ & 0.014 \\
\hline \multicolumn{5}{|c|}{ Average monthly shallow-dose equivalent } \\
\hline Nurse & $40.9 \pm 13.0$ & $24.2 \pm 7.1$ & $-16.5(-40.6 \%)$ & $<0.0001$ \\
\hline Technologist & $46.3 \pm 12.7$ & $26.9 \pm 7.5$ & $-19.4(-41.9 \%)$ & $<0.0001$ \\
\hline Administrative & $3.6 \pm 1.8$ & $2.9 \pm 1.7$ & $-0.77(-21.3 \%)$ & 0.04 \\
\hline \multicolumn{5}{|c|}{ Shallow-dose equivalent per 1,000 patients } \\
\hline Nurse & $139.3 \pm 17.5$ & $74.1 \pm 8.5$ & $-65.2(-46.8 \%)$ & $<0.0001$ \\
\hline Technologist & $157.3 \pm 24.9$ & $83.8 \pm 9.5$ & $-73.5(-46.7 \%)$ & $<0.0001$ \\
\hline Administrative & $13.4 \pm 4.2$ & $9.7 \pm 3.2$ & $-3.7(-27.4 \%)$ & 0.04 \\
\hline \multicolumn{5}{|c|}{ Average monthly lens-dose equivalent } \\
\hline Nurse & $41.5 \pm 11.2$ & $24.5 \pm 7.1$ & $-17.0(-41.0 \%)$ & $<0.0001$ \\
\hline Technologist & $46.2 \pm 11.5$ & $27.1 \pm 7.6$ & $-19.1(-41.3 \%)$ & $<0.0001$ \\
\hline Administrative & $3.9 \pm 2.0$ & $2.5 \pm 1.5$ & $-1.4(-36.0 \%)$ & 0.001 \\
\hline \multicolumn{5}{|c|}{ Lens-dose equivalent per 1,000 patients } \\
\hline Nurse & $142.0 \pm 18.3$ & $75.1 \pm 8.1$ & $-67.0(-47.1 \%)$ & $<0.0001$ \\
\hline Technologist & $157.1 \pm 20.4$ & $84.6 \pm 9.8$ & $-72.5(-46.1 \%)$ & $<0.0001$ \\
\hline Administrative & $13.7 \pm 5.2$ & $8.8 \pm 2.8$ & $-5.0(-36.1 \%)$ & 0.019 \\
\hline
\end{tabular}

represent $2 \%$ of the acceptable annual total. The annual limit for shallow-dose equivalent is 50 rems $(50,000 \mathrm{mrem})$, and the nurses and technologists averaged between 490 and 560 mrem annually in period 1 and between 290 and 330 mrem in period 2. The period 2 values represent $0.7 \%$ of the acceptable annual total.

\section{Confounders}

Potential confounding variables that would affect the total activity or the length of exposure to the activity include the number of patients imaged in the laboratory, the amount of ${ }^{99 \mathrm{~m} T c}$ used, the percentage of ${ }^{201} \mathrm{Tl}$ studies, the proportion of stress-only studies, and the amount of time the patients spent in the laboratory (Table 4). In period 2, the total activity of ${ }^{99 \mathrm{~m}} \mathrm{Tc}$ used per month and the mean ${ }^{99 \mathrm{~m}} \mathrm{Tc}$ administered activity per patient decreased, and more patients had stress-only imaging, which would be expected to result in a lower radiation exposure to staff. Also, the number of ${ }^{201} \mathrm{Tl}$ tests increased in period 2, with expected lower exposure to the laboratory staff. However, the number of patients studied per month increased in period 2 and there was no significant difference in the total patient time spent in the laboratory (a total of 49,737.5 \pm 4,570.9 min vs. 47,127.5 \pm 5,144.1 $\min , P=0.19$ ).

\section{Patient Dose Reduction}

Because the dose administered to patients is so strongly related to the radiation exposure of the medical staff, we explored the degree of reduction in the average administered ${ }^{99 \mathrm{~m}} \mathrm{Tc}$ activity that was attributable to the introduction of high-efficiency SPECT camera technology versus the use of stress-only protocols (Tables 5 and 6). By comparing mean patient doses from periods 1 and 2, we calculated a reduction of $9.6 \mathrm{mCi}$ of total activity $(28.8 \%)$ due to the change from conventional SPECT to high-efficiency

TABLE 3

Mean Annual Radiation Exposure by Staff Position in Millirems with Percentage of Annual Occupational Exposure Limits

\begin{tabular}{|c|c|c|c|}
\hline Parameter & Annual limit & Period 1 (before) & Period 2 (after) \\
\hline Deep-dose equivalent & 5,000 & & \\
\hline Nurse & & $490.8(9.8 \%)$ & $294.0(5.9 \%)$ \\
\hline Technologist & & $528.0(10.6 \%)$ & $334.8(6.7 \%)$ \\
\hline Administrative & & $43.2(0.9 \%)$ & $27.6(0.6 \%)$ \\
\hline Shallow-dose equivalent & 50,000 & & \\
\hline Nurse & & $490.8(1.0 \%)$ & $290.4(0.6 \%)$ \\
\hline Technologist & & $555.6(1.1 \%)$ & $331.2(0.7 \%)$ \\
\hline Administrative & & $43.2(0.09 \%)$ & $34.8(0.07 \%)$ \\
\hline Lens-dose equivalent & 15,000 & & \\
\hline Nurse & & $500.4(3.3 \%)$ & $294(2.0 \%)$ \\
\hline Technologist & & $554.4(3.7 \%)$ & $334.8(2.2 \%)$ \\
\hline Administrative & & $46.8(0.3 \%)$ & $30.0(0.2 \%)$ \\
\hline
\end{tabular}


TABLE 4

Potential Confounding Variables That Would Affect Staff Radiation Exposure

\begin{tabular}{|c|c|c|c|c|}
\hline Parameter & Period 1 (before) & Period 2 (after) & Change & $P$ \\
\hline Total 99mTc used (mCi) & $10,745.9 \pm 1,008.2$ & $7,174.2 \pm 760.0$ & $-3,571.7 \pm 1,040.8(-33.2 \%)$ & $<0.0001$ \\
\hline Mean ${ }^{99 m T c}$ dose $(\mathrm{mCi})$ & $36.5 \pm 0.66$ & $23.8 \pm 1.2$ & $-12.7 \pm 1.3$ & $<0.0001$ \\
\hline No. of patients & $295 \pm 26$ & $325 \pm 31$ & $29.9 \pm 34.5$ & 0.01 \\
\hline Patient time (min) & $49,737.5 \pm 4,570.9$ & $47,127.5 \pm 5,144.1$ & $-2,610.0 \pm 6,497.2(-5.2 \%)$ & 0.19 \\
\hline Percentage stress-only & $35.0 \% \pm 3.8 \%$ & $55.9 \% \pm 4.1 \%$ & $-20.9 \% \pm 6.2 \% \quad(59.6 \%)$ & $<0.0001$ \\
\hline
\end{tabular}

Data are average monthly values.

SPECT. By comparing the difference in average total patient dose between stress-only and full (rest-stress) studies from both periods, we found a $14.9-\mathrm{mCi}$ reduction in administered activity $(40.7 \%)$ due to the use of a stress-only protocol. The combination of these 2 interventions resulted in a $34.7 \%$ reduction in mean patient total ${ }^{99 \mathrm{~m}} \mathrm{Tc}$ administered activity between periods, with camera technology being responsible for $39.2 \%$ of the reduction and stress-only protocols for $60.8 \%$. The effect of varying degrees of incorporation of stress-only protocols and high-efficiency camera technology on potential dose reduction of a standard (14) $10-\mathrm{mCi} / 30-\mathrm{mCi}$ rest-stress protocol can be seen in Figure 1 . The average ${ }^{201} \mathrm{Tl}$ administered activity also decreased from 3.8 to $2.7 \mathrm{mCi}$ between periods 1 and 2 . However, because of the proportionally small number of ${ }^{201} \mathrm{Tl}$ studies, the change in staff radiation exposure was considered negligible for the purpose of this study.

\section{DISCUSSION}

Despite recent attention to the exposure of patients to radiation from medical imaging $(15,16)$, there is little published literature on the exposure of medical staff to radiation in a noninvasive cardiology laboratory. Previous studies have examined the incidence of cancers in health care workers with occupational radiation exposure or in their offspring $(17,18)$, as well as measuring short-term exposure to staff performing studies with various isotopes $(19,20)$. None of these studies assessed changes in study protocols beyond attention to shielding as a way to reduce exposure. Our study demonstrated a decrease in radiation dose equivalent to nuclear cardiology personnel achieved by a combination of dose reduction and use of stress-only imaging. Also, it appears that exposure to administrative personnel and to the patients in the waiting area is negligible.

A $40 \%$ reduction in staff dose equivalent was seen between the 2 periods and was achieved by a $35 \%$ reduction in the average ${ }^{99 \mathrm{~m} T c}$ patient administered activity and a $60 \%$ increase in the proportion of stress-only studies. Of the confounding factors that changed between the 2 periods, these factors played the largest role in reducing radiation exposure and even outweighed an increase in patient volume. Despite several attempts at statistical modeling, more than $75 \%$ of the variability in radiation exposure could not be attributed to individual effects, because of confounding variables present in both periods that could not be untangled. The decrease in administered activity was made possible by the adoption of new technology (high-efficiency SPECT), and the increase in stress-only studies was made possible by the adoption of new imaging protocols. High-efficiency SPECT cameras allowed for lower administered patient doses and shorter imaging times (less time for staff to be exposed). Previous work with high-efficiency SPECT has demonstrated the feasibility of even lower administered doses ( 6 ) as well as even shorter imaging times (21). Stress-only protocols were the other contributor to the reduction in patient doses and decreased patient time spent in the lab. Stress-first imaging is more labor-intensive, as it requires appropriate patient selection and then review of images immediately after stress imaging to determine the need for rest images. Some form of attenuation correction, ${ }^{153} \mathrm{Gd}$ line source, CT, or prone imaging is necessary to increase the proportion of normal stress images to an acceptable level. Because this study represented real-world changes in our noninvasive laboratory, unfortunately both these variables (the adoption of new high-efficiency SPECT cameras and a greater use of stress-only protocols) changed between the 2 periods, making the determination of their individual contributions to staff exposure reduction problematic because of confounding. The relative merits of each of these changes to reducing staff exposure when applied individually to other laboratories are not definitively quantified but will still be due to reducing patient isotope doses, eliminating rest doses, shortening imaging time, and reducing the time patients spend in the noninvasive laboratory.

Changes in study protocol and administered activity between the periods in the current study resulted in reduced radiation exposure to the patient as well. We saw a $35 \%$ reduction in radiation exposure to the patient based on the mean total ${ }^{99 \mathrm{~m}} \mathrm{Tc}$ administered activity ( 36.5 vs. $23.8 \mathrm{mCi}$ ). The American Society

TABLE 5

Decrease in 99mTc Doses in Millicuries Based on SPECT Camera Technology and Use of Stress-Only Protocol Calculated from 2 Periods (Conventional and CZT SPECT Cameras) and 2 Protocols (Full Study and Stress-Only)

\begin{tabular}{|c|c|c|c|c|c|c|}
\hline \multirow[b]{2}{*}{ Study } & \multicolumn{3}{|c|}{ Period 1 (before) } & \multicolumn{3}{|c|}{ Period 2 (after) } \\
\hline & Stress dose & Rest dose & Total dose & Stress dose & Rest dose & Total dose \\
\hline Full & $30.9 \pm 3.5$ & $11.3 \pm 4.1$ & $42.2 \pm 5.1$ & $21.9 \pm 5.8$ & $9.5 \pm 6.9$ & $31.5 \pm 8.9$ \\
\hline Stress-only & $26.2 \pm 7.9$ & 0 & $26.2 \pm 7.9$ & $17.8 \pm 7.4$ & 0 & $17.8 \pm 7.4$ \\
\hline
\end{tabular}


TABLE 6

Decrease in ${ }^{99 m}$ Tc Doses in Millicuries Based on SPECT Camera Technology and Use of Stress-Only Protocol

\begin{tabular}{lccc}
\hline Change due to... & Stress dose & Rest dose & Total dose \\
\hline Camera type & -8.7 & -1.8 & -9.6 \\
Stress-only study & -4.4 & -10.4 & -14.9 \\
\hline
\end{tabular}

of Nuclear Cardiology has set a goal of no more than a 9-mSv patient exposure in 50\% of studies by 2014 (22). The implementation of one or both of these new techniques, stress-only imaging or high-efficiency SPECT camera technology, should be adequate to achieve this goal (Fig. 1). The largest reduction in radiation exposure to the patient was achievable through the use of stressonly imaging $(41 \%)$, with a smaller degree of reduction achievable with high-efficiency SPECT cameras (29\%). Adopting a stressfirst approach to imaging is a particularly feasible option for all laboratories, as the expected frequency of normal stress studies using appropriateness criteria for the performance of MPI exceeds $50 \%(21)$ and the proportion of normal studies in the large published nuclear cardiology cohorts reaches up to $70 \%(23,24)$. Although purchasing new camera technology may not be feasible for all because of its cost, new half-time imaging software for traditional NaI cameras has also been shown to decrease administered activity. New software technology using iterative image reconstruction with resolution recovery improves count statistics and suppresses noise by correctly accounting for formerly suppressed counts (25). All major SPECT camera manufacturers offer advanced image reconstruction software: Philips (Astonish), GE Healthcare (Evolution), Siemens (Flash3D), Digirad (nSPEED), and a third-party company (UltraSPECT) (26). These algorithms have been validated and revealed the ability for at least half-time

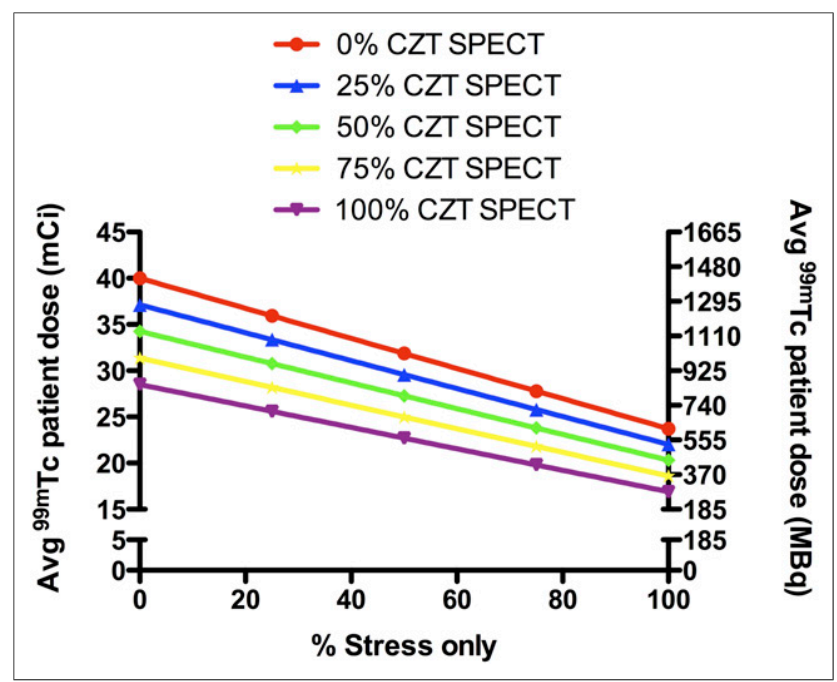

FIGURE 1. Possible reduction in total patient dose based on traditional $10-\mathrm{mCi} / 30-\mathrm{mCi}$ rest-stress ${ }^{99 \mathrm{mT}} \mathrm{Tc}$ protocol with variable use of stress-only protocols and high-efficiency SPECT camera technology. Data are based on the following equation: adjusted dose $=$ $40 \mathrm{mCi} \times(1-\%$ use of stress only $\times 0.407) \times(1-\%$ use of CZT SPECT $\times 0.288$ ), where $40.7 \%$ is the reduction obtainable from $100 \%$ stress-only use and $28.8 \%$ is the reduction obtainable from $100 \%$ CZT SPECT use, calculated from Tables 5 and 6. acquisition or halved administered doses without the loss of image quality or diagnostic utility (27-29).

The study was limited by the single-site clinical experience and the small number of staff members sampled. However, the large number of patient studies performed during this time should reduce the variability in the staff exposure. Although the study was not randomized or masked, the noninvasive laboratory staff was the same during the 2 periods and the preparation of doses, administration of doses during stress testing, and performance of stress tests did not change between the 2 periods. Although the imaging times changed with introduction of the high-efficiency SPECT cameras, the technologists were still required to directly observe patients (for motion) during imaging and the room sizes and shielding in the camera rooms did not change between the periods. The medical staff in the noninvasive laboratory is expected to wear their radiation badges on their lab coats at all times during work hours as terms of their employment; however, compliance was not independently verified during the study period. The effect of any month-to-month variations in the time that personnel actually spent in the noninvasive laboratory (due, for example, to sick days and vacations) was presumably minimized or eliminated altogether by use of data from a whole year. Because the study reflects real-world experience in which 2 variables were changing at the same time (new camera technology and greater use of stress-only imaging), determination of the individual contribution of each of these variables to the overall reduction in staff exposure is, unfortunately, problematic. During period 2, a few patients were imaged with a conventional SPECT camera because of patient comorbidities such as morbid obesity or physical handicaps that prevented them from being positioned properly in the smaller high-efficiency camera. This continued minimal use of conventional SPECT during period 2 likely caused an underestimation of the radiation exposure reduction due to high-efficiency SPECT. Also during period 2, a few patients were imaged with ${ }^{201} \mathrm{Tl}$ because of ${ }^{99 \mathrm{~m}} \mathrm{Tc}$ shortages, and ${ }^{201} \mathrm{Tl}$ differs from ${ }^{99 \mathrm{~m}} \mathrm{Tc}$ in exposure characteristics to the patient (greater effective dose) and staff (less exposure). We felt that the small number of patients imaged with ${ }^{201} \mathrm{Tl}$ would be negligible compared with the contribution of the greater number of ${ }^{99 m} \mathrm{Tc}$-imaged patients. The radiation exposure contribution of ${ }^{153} \mathrm{Gd}$ line sources used for attenuation correction during period 1 but not period 2 was not controlled for in the analysis but is expected to be low (an effective dose of 0.001-0.01 $\mathrm{mSv}$ to the patient) (30).

\section{CONCLUSION}

A combination of selective use of stress-only protocols and high-efficiency SPECT technology significantly reduced the occupational radiation dose equivalent to the staff of a nuclear cardiology laboratory. The average administered isotope dose could be significantly reduced as a result of the lower doses needed with the CZT camera, and the need for a rest injection was avoided by using a stress-only protocol.

\section{DISCLOSURE}

The costs of publication of this article were defrayed in part by the payment of page charges. Therefore, and solely to indicate this fact, this article is hereby marked "advertisement" in accordance with 18 USC section 1734 . No potential conflict of interest relevant to this article was reported. 


\section{REFERENCES}

1. Einstein AJ, Moser KW, Thompson RC, Cerqueira MD, Henzlova MJ. Radiation dose to patients from cardiac diagnostic imaging. Circulation. 2007;116:12901305.

2. Fazel R, Krumholz HM, Wang Y, et al. Exposure to low-dose ionizing radiation from medical imaging procedures. N Engl J Med. 2009;361:849-857.

3. Henzlova MJ, Duvall WL. The future of SPECT MPI: time and dose reduction. J Nucl Cardiol. 2011;18:580-587.

4. Duvall WL, Croft LB, Godiwala T, Ginsberg E, George T, Henzlova MJ. Reduced isotope dose with rapid SPECT MPI imaging: initial experience with a CZT SPECT camera. J Nucl Cardiol. 2010;17:1009-1014.

5. Nkoulou R, Pazhenkottil AP, Kuest SM, et al. Semiconductor detectors allow low-dose-low-dose 1-day SPECT myocardial perfusion imaging. J Nucl Med. 2011;52:1204-1209.

6. Duvall WL, Croft LB, Ginsberg ES, et al. Reduced isotope dose and imaging time with a high-efficiency CZT SPECT camera. J Nucl Cardiol. 2011;18:847-857.

7. DePuey EG, Bommireddipalli S, Clark J, Leykekhman A, Thompson LB, Friedman M. A comparison of the image quality of full-time myocardial perfusion SPECT vs wide beam reconstruction half-time and half-dose SPECT. J Nucl Cardiol. 2011;18:273-280.

8. Gimelli A, Bottai M, Genovesi D, Giorgetti A, Di Martino F, Marzullo P. High diagnostic accuracy of low-dose gated-SPECT with solid-state ultrafast detectors: preliminary clinical results. Eur J Nucl Med Mol Imaging. 2012;39:83-90.

9. Slomka PJ, Patton JA, Berman DS, Germano G. Advances in technical aspects of myocardial perfusion SPECT imaging. J Nucl Cardiol. 2009;16:255-276.

10. Chang SM, Nabi F, Xu J, Raza U, Mahmarian JJ. Normal stress-only versus standard stress/rest myocardial perfusion imaging: similar patient mortality with reduced radiation exposure. J Am Coll Cardiol. 2010;55:221-230.

11. Duvall WL, Wijetunga MN, Klein TM, et al. The prognosis of a normal stress-only Tc-99m myocardial perfusion imaging study. J Nucl Cardiol. 2010;17:370-377.

12. Gibson PB, Demus D, Noto R, Hudson W, Johnson LL. Low event rate for stressonly perfusion imaging in patients evaluated for chest pain. J Am Coll Cardiol. 2002;39:999-1004.

13. Hansen CL, Goldstein RA, Berman DS, et al. Myocardial perfusion and function single photon emission computed tomography. J Nucl Cardiol. 2006;13:e97-e120.

14. Henzlova MJ, Cerqueira MD, Hansen CL, Taillefer R, Yao SS. ASNC announcement. J Nucl Cardiol. 2009;16:331.

15. Einstein AJ. Effects of radiation exposure from cardiac imaging: how good are the data? J Am Coll Cardiol. 2012;59:553-565.

16. Einstein AJ. Medical imaging: the radiation issue. Nat Rev Cardiol. 2009;6:436438.
17. Roguin A, Goldstein J, Bar O. Brain tumours among interventional cardiologists: a cause for alarm? Report of four new cases from two cities and a review of the literature. EuroIntervention. 2012;7:1081-1086.

18. Johnson KJ, Alexander BH, Doody MM, et al. Childhood cancer in the offspring born in 1921-1984 to US radiologic technologists. Br J Cancer. 2008;99:545550 .

19. Schurnbrand P, Schicha H, Thal H, Emrich D. External radiation exposure of

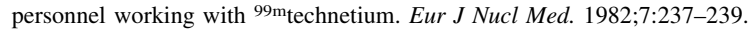

20. Kristoffersen US, Gutte H, Skovgaard D, Andersen PA, Kjaer A. Radiation exposure for medical staff performing quantitative coronary perfusion PET with ${ }^{13}$ N-ammonia. Radiat Prot Dosimetry. 2010;138:107-110.

21. Slomka PJ, Dey D, Duvall WL, Henzlova MJ, Berman DS, Germano G. Advances in nuclear cardiac instrumentation with a view towards reduced radiation exposure. Curr Cardiol Rep. 2012;14:208-216.

22. Cerqueira MD, Allman KC, Ficaro EP, et al. Recommendations for reducing radiation exposure in myocardial perfusion imaging. J Nucl Cardiol. 2010;17: 709-718.

23. Hachamovitch R, Berman DS, Shaw LJ, et al. Incremental prognostic value of myocardial perfusion single photon emission computed tomography for the prediction of cardiac death: differential stratification for risk of cardiac death and myocardial infarction. Circulation. 1998;97:535-543.

24. Hachamovitch R, Hayes SW, Friedman JD, Cohen I, Berman DS. Comparison of the short-term survival benefit associated with revascularization compared with medical therapy in patients with no prior coronary artery disease undergoing stress myocardial perfusion single photon emission computed tomography. Circulation. 2003;107:2900-2907.

25. Borges-Neto S, Pagnanelli RA, Shaw LK, et al. Clinical results of a novel wide beam reconstruction method for shortening scan time of Tc-99m cardiac SPECT perfusion studies. J Nucl Cardiol. 2007;14:555-565.

26. Travin MI. Cardiac cameras. Semin Nucl Med. 2011;41:182-201.

27. DePuey EG, Gadiraju R, Clark J, Thompson L, Anstett F, Shwartz SC. Ordered subset expectation maximization and wide beam reconstruction "half-time" gated myocardial perfusion SPECT functional imaging: a comparison to "fulltime" filtered backprojection. J Nucl Cardiol. 2008;15:547-563.

28. Bateman TM, Heller GV, McGhie AI, et al. Multicenter investigation comparing a highly efficient half-time stress-only attenuation correction approach against standard rest-stress Tc-99m SPECT imaging. J Nucl Cardiol. 2009;16:726-735.

29. Valenta I, Treyer V, Husmann L, et al. New reconstruction algorithm allows shortened acquisition time for myocardial perfusion SPECT. Eur J Nucl Med Mol Imaging. 2010;37:750-757.

30. Depuey EG, Mahmarian JJ, Miller TD, et al. Patient-centered imaging. J Nucl Cardiol. 2012;19:185-215. 